\title{
ORGANIZAÇÃO E ACESSO À INFORMAÇÃO NO AMBIENTE UNIVERSITÁRIO
}

\author{
ORGANIZACIÓN Y ACCESO A LA INFORMACIÓN EN \\ EL AMBIENTE UNIVERSITARIO
}

Maria Leandra Bizello*

\begin{abstract}
RESUMO:
Introdução: Este trabalho objetiva discutir a Lei de Acesso à Informação no âmbito das universidades e de maneira mais pontual a implantação da LAI na Universidade Estadual Paulista "Júlio de Mesquita Filho" - UNESP. Objetivo: Faz um estudo da importância da gestão de documentos para a organização e representação da informação nas universidades. Metodologia: A metodologia utilizada foi a da pesquisa bibliográfica em um primeiro momento uma vez que a discussão sobre a lei de acesso à informação é relativamente nova. Exploramos o tema de maneira qualitativa e objetivamos discuti-lo na UNESP sem deixar de cotejar de maneira geral a universidade como instituição. Resultados: Assim o trabalho apresenta resultados iniciais cruzando a discussão bibliográfica e a pesquisa de caráter observacional. Conclusões: A Lei de Acesso à Informação impulsionou uma maior visibilidade aos arquivos universitários, no caso o da UNESP, sendo que a organização arquivística e a construção de instrumentos de avaliação documental proporcionaram as bases para a operacionalização de sistemas mais integrados além de dar maior subsídio ao Serviço de Informação ao Cidadão.
\end{abstract}

Palavras-chave: Lei de Acesso à informação. Gestão de documentos. Arquivo. Universidade. Avaliação de documentos.

\section{INTRODUÇÃO}

Este trabalho tem como objetivo refletir sobre a Lei de Acesso à Informação - LAI - no ambiente universitário e mais especificamente sobre a

*Doutora em Multimeios pela Universidade Estadual de Campinas. Docente Programa Pós-Graduação em Ciência da Informação UNESP. E-mail: mleandra23@gmail.com. 
implantação da lei na Universidade Estadual Paulista "Júlio de Mesquita Filho" - UNESP. Refletiremos também sobre as relações que o acesso à informação estabelece com a gestão de arquivos em universidades.

O acesso à informação pública tomou grande importância no Brasil com a abertura política nos anos de 1980. O contexto de fim da ditadura militar e impulso da democracia enquanto perspectiva futura para o Estado brasileiro permitiu que o acesso à informação fosse contemplado na constituição de 1988 ainda que timidamente. Apesar do reconhecimento do direito à informação, o aspecto do sigilo predominava frente ao acesso.

A cidadania plena estava um tanto longe em seu exercício uma vez que o Estado ainda tateava em dar condições para que a população tivesse os direitos fundadores da cidadania: direitos civis, direitos políticos e direitos sociais. Essa conquista no Brasil ainda é marcada por legados históricos relevantes na sociedade como a escravidão e a desigualdade social.

Por outro lado, a Lei de Arquivos, Lei 8.159 de 8 de janeiro de 1991, foi mais incisiva nas questões referentes ao acesso à informação se bem que preocupada em orientar e normatizar os procedimentos arquivísticos no Brasil.

As universidades públicas brasileiras também tiveram que se adequar à Lei de Acesso à Informação organizando seus arquivos e constituindo os serviços de atendimento ao cidadão. Nesse sentido a UNESP, universidade pública paulista criada em 1976 a partir da incorporação de diversas instituições de ensino superior no interior do estado de São Paulo, também movimenta-se tanto para proporcionar dados e informações de maneira transparente quanto atender plenamente os cidadãos.

Entretanto, a UNESP não possui um sistema de arquivos implantado, as Seções Técnicas de Comunicações, lugar onde funciona o protocolo e tem as atribuições de arquivo são responsáveis pelo controle dos documentos de arquivo assim como de todo o processo de avaliação documental. Elas ainda exercem o Serviço de Informações ao Cidadão uma vez que concentram a maioria dos documentos produzidos em cada campi. Compreendemos, então, que o trabalho arquivístico diferenciado não significa que documentos, arquivos e informações não estejam organizados e em acesso. Isso nos dá a dimensão

Inf. Inf., Londrina, v. 22, n. 2, p. 497 - 510, maio/ago., 2017. 
que a reflexão arquivística não se centra apenas no documento de arquivo, mas em um amplo espectro dos arquivos.

\section{ALGUMAS REFLEXÕES SOBRE A LEI DE ACESSO À INFORMAÇÃO - LAI}

A Lei de Acesso à Informação n ${ }^{\circ} 12.527$ de 18 de novembro de 2011 entrou em vigor no dia 16 de maio de 2012, sendo nesse período regulamentada pelo poder executivo federal. A LAI (como é mais conhecida) também deve ser regulamentada nos outros âmbitos de poder da União, em Estados e Municípios.

A abrangência da LAl atinge todos os órgãos e entidades públicas de todos os poderes da Federação e em todos os seus âmbitos. Abrange também as entidades privadas sem fins lucrativos que recebem recursos públicos.

Desde a Constituição de 1988 há a garantia ao direito à informação. Para as sociedades democráticas esse direito é um dos pilares básicos para o amplo exercício da cidadania; ela é então um direito civil, político e social.

O Brasil ao promulgar e regulamentar a LAl em todos os âmbitos da Federação segue uma tendência internacional de países que possuem a Lei de Acesso à Informação como o Chile, o Uruguai e os Estados Unidos no continente americano, a Índia e a Inglaterra. A Suécia é o país precursor em legislar o acesso à informação, a lei sueca é de 1766.

A definição de informação segundo a LAl está no inciso I do Artigo $4^{\circ}$ :

I - informação: dados, processados ou não que podem ser utilizados para produção e transmissão de conhecimento, contidos em qualquer meio, suporte ou formato. (BRASIL, 2011, on-line).

Assim definida, todo e qualquer cidadão e cidadã tem direito as informações produzidas e custodiadas pelo poder público, se tais informações não forem classificadas como sigilosas, devem estar disponíveis para acesso. No artigo $5^{\circ}$ o Estado garante tal direito e ainda franqueia a informação "[...] 
mediante procedimentos objetivos e ágeis, de forma transparente, clara e em linguagem de fácil compreensão". (BRASIL, 2011, on-line).

O Estado deve assegurar o acesso à informação segundo cinco diretrizes básicas orientadas no artigo $3^{\circ}$ :

I - observância da publicidade como preceito geral e do sigilo como exceção;

II - divulgação de informações de interesse público, independentemente de solicitações;

III - utilização de meios de comunicação viabilizados pela tecnologia da informação;

IV - fomento ao desenvolvimento da cultura de transparência na administração pública;

$\mathrm{V}$ - desenvolvimento do controle social da administração pública. (BRASIL, 2011, on-line).

Notamos que o acesso à informação implica em conhecer a informação que está registrada em um suporte, seja ele qual for. A LAI considera, assim, o documento, em seu artigo $4^{\circ}$ como "unidade de registro de informações, qualquer que seja o suporte ou formato" (BRASIL, 2011, on-line). Há, portanto, a necessidade de gestão de documentos de arquivo, uma vez que os documentos são produzidos e recebidos por entidades e instituições públicas e privadas contempladas na LAI. Em concomitância, é necessária a gestão da informação, pois a própria lei entende que a informação está registrada em um suporte. Assim para que a LAI possa ser colocada em prática é fundamental que os documentos de arquivo sejam tratados e organizados.

O/A cidadão/cidadã tem o direito de obter, segundo o artigo $7^{0}$ :

I - orientação sobre os procedimentos para a consecução de acesso, bem como sobre o local onde poderá ser encontrada ou obtida a informação almejada;

II - informação contida em registros ou documentos, produzidos ou acumulados por seus órgãos ou entidades, recolhidos ou não a arquivos públicos;

III - informação produzida ou custodiada por pessoa física ou entidade privada decorrentes de qualquer vínculo com seus órgãos ou entidades, mesmo que esse vínculo já tenha cessado; IV - informação primária, íntegra, autêntica e atualizada; V - informação sobre atividades exercidas pelos órgãos e entidades, inclusive as realtivas à sua política, organização e serviços; 
VI - informação pertinente à administração do patrimônio público, utilização de recursos públicos, licitação, contratos administrativos; e

VII - informação relativa:

a) à implementação, acompanhamento e resultados dos programas, projetos e ações dos órgãos e entidades públicas, bem como metas e indicadores propostos;

b) ao resultado de inspeções, auditorias, prestações e tomadas de contas realizadas pelos órgãos de controle interno e externo, incluindo prestações de contas relativas a exercícios anteriores.

$\S 1^{\circ} \mathrm{O}$ acesso à Informação previsto no caput não compreende as informações referentes a projetos de pesquisa e desenvolvimento científicos ou tecnológicos cujo sigilo seja imprescindível à segurança da sociedade e do Estado. (BRASIL, 2011, on-line).

No entanto, a LAl estabelece categorias de informação, segundo Smit e Lattouf (2014): a) informação de interesse coletivo ou geral (art. 8); b) informação de interesse público (art. 10); c) informação sigilosa (inciso III do art. 4 e art. 24); e d) informações pessoais (inciso IV do art. 4 e art.31). Para cada uma dessas categorias há critérios e regras de acesso (SMIT; LATTOUF, 2014). Além disso, as informações devem ser classificadas segundo o grau de sigilo: ultrassecreta: 25 (vinte e cinco) anos; secreta: 15 (quinze) anos e reservada: 5 (cinco) anos (BRASIL, 2011, on-line) ${ }^{1}$, tais prazos vigoram a partir da data da produção do documento/informação. O capítulo IV da lei estabelece as restrições ao acesso à informação, respeita e, segundo o art. 22, da Seção I,

[...] não exclui as demais hipóteses legais de sigilo e de segredo de justiça nem as hipóteses de segredo industrial decorrentes da exploração direta de atividade econômica pelo Estado ou por pessoa física ou entidade privada que tenha qualquer vínculo com o poder público. (BRASIL, 2011, on-line)

Dessa maneira, a LAI ao estabelecer os prazos de restrição também contempla os prazos já determinados por outras leis em vigor. O estabelecimento do grau de sigilo também é de competência dos diversos

${ }^{1}$ Cf. $\S 1^{\circ}$ do art. 24

Inf. Inf., Londrina, v. 22, n. 2, p. 497 - 510, maio/ago., 2017. http:www.uel.br/revistas/informacao/ 
âmbitos da federação, ou seja, estados e municípios; os órgãos e autarquias municipais e estaduais devem estabelecer os graus de sigilo às informações que produzem. Nesse mesmo sentido, recorremos à análise criteriosa de Smit e Lattouf (2014, p.120)

A lei não impõe a obrigatoriedade de classificação de informações e documentos em grau de sigilo. A análise da necessidade de sigilo está sob a responsabilidade da Administração pública nas hipóteses previstas na lei. No seu âmbito de atuação, a Administração pública pode estabelecer critérios, observadas as hipóteses legais, que justifiquem a classificação em grau de sigilo.

Para Jardim (2012, p.7)

Nos planos estadual e municipal, o vazio jurídico manteve-se até a aprovação da LAl e contribuiu para a sobrevivência da opacidade e do "segredismo", típicos do Estado brasileiro.

Ainda segundo Jardim (2012, p.7), mesmo que a lei garanta e assegure o acesso à informação em todos os âmbitos e entenda o cidadão/cidadã como o seu principal sujeito, na medida em que a aciona, ele reconhece que a

[...] LAl supõe um grau de ordenamento informacional do Estado brasileiro que ainda está longe de existir, em que pese ilhas de excelência e setores com maiores teores de gestão da informação.

Para que o/a cidadão/cidadã tenha o acesso à informação assegurado a LAl em seu artigo $9^{\circ}$ estabelece:

I - criação de serviço de informações ao cidadão, nos órgãos e entidades do poder público, em local com condições apropriadas para:

a) atender e orientar o público quanto ao acesso a informações;

b) informar sobre a tramitação de documentos nas suas respectivas unidades;

c) protocolizar documentos e requerimentos de acesso a informações; e

II - realização de audiências ou consultas públicas, incentivo à participação popular ou a outras formas de divulgação. (BRASIL, 2011, on-line).

Os órgãos e entidades públicas devem divulgar suas informações em locais de fácil acesso; é "obrigatória a divulgação em sítios oficiais da rede

Inf. Inf., Londrina, v. 22, n. 2, p. 497 - 510, maio/ago., 2017. http:www.uel.br/revistas/informacao/ 
mundial de computadores (internet)" ( $§ 2^{\circ}$ do artigo $8^{\circ}$, BRASIL, 2011, on-line). A ênfase é clara na facilidade e grande publicização que deve ser dada à informação, assim como o estabelecimento de local e infraestrutura para que o cidadão, inclusive o deficiente, possa comunicar-se com o órgão ou entidade do sítio em que solicita a informação.

O Serviço de Informação ao Cidadão (SIC) é a transparência passiva, ou seja, é a obrigação do Estado em atender com exatidão e no prazo combinado as solicitações dos cidadãos/cidadãs que recorrem ao órgão ou entidade para obter a informação desejada. Os artigos 10 e 11 tratam do pedido de acesso à informação, deles destacamos:

1. qualquer pessoa pode apresentar pedido de acesso à informação, deverá identificar-se e especificar a informação;

2. o órgão ou entidade não pode impor critérios de identidade;

3. caso o cidadão/cidadã não tenha acesso á internet para fazer a solicitação o órgão ou entidade deve apresentar alternativa de encaminhamento das solicitações de acesso;

4. o cidadão/cidadã não precisa justificar sua solicitação;

5. a autorização ou concessão ao acesso à informação deve ser imediato, caso isso não seja possível, o órgão ou entidade tem o prazo de 20 dias, com prorrogação de mais 10 dias para a resposta.

6. a recusa à informação deve ser justificada com razões de fato e de direito;

7. comunicar que não possui a informação e indicar quem a possui. (BRASIL, 2011, on-line).

A transparência ativa pressupõe obrigações mínimas do Estado em divulgar de maneira espontânea informações referentes à sua estrutura organizacional, horários, locais de atendimento ao público, despesas, repasses e transferências, procedimentos licitatórios, contratos e convênios celebrados, perguntas mais frequentes.

Há uma forte relação entre a concepção da LAl e sua aplicação com as noções de transparência ativa e passiva. A ideia de transparência dos governos é evidente apesar de podermos questionar se ela existe, é eficiente ou desejada de fato pelo estado.

Inf. Inf., Londrina, v. 22, n. 2, p. 497 - 510, maio/ago., 2017. http:www.uel.br/revistas/informacao/ 


\subsection{Decreto $\mathrm{n}^{\circ} \mathbf{5 8 . 0 5 2}$ - A regulamentação da LAl no Estado de São Paulo}

$O$ decreto $n^{\circ} 58.052$, de 16 de maio de 2012, regulamenta no Estado de São Paulo, a Lei federal $n^{\circ} 12.527$, de 18 de novembro de 2011, isto é, o decreto operacionaliza a lei no âmbito estadual. É importante assinalar que o decreto estadual coloca em destaque o acesso a documentos, dados e informações. $\mathrm{O}$ inciso II do artigo $2^{\circ}$ é uma exigência para assegurar o acesso à informação: "implementação da política estadual de arquivos e gestão de documentos" (SÃO PAULO, 2012, on-line). Enquanto a LAI considera e define documento, o decreto estadual paulista, aprofunda tal noção ao especificar que o documento é o documento de arquivo, no inciso IX, e definir gestão de documentos, no inciso XII, ambos estabelecidos no artigo $2^{\circ}$. Dessa forma, há uma relação intrínseca estipulada no decreto entre documento de arquivo e informação, e da gestão de documentos e da informação governamental.

No âmbito federal a responsabilidade pela aplicação da LAl é da Controladoria-Geral da União (CGU). No estado de São Paulo é o Arquivo Público do Estado de São Paulo o órgão que cuida da gestão da informação, é dele que emana as propostas de "normas, procedimentos e requisitos técnicos complementares, visando o tratamento da informação"2. No artigo $9^{\circ} \circ$ Arquivo Público tem a finalidade de:

I - coordenar a integração sistêmica dos Serviços de
Informações ao Cidadão - SIC, instituídos nos órgãos e
entidades; II - realizar a consolidação e sistematização de dados
a que se refere o artigo 26 deste decreto, bem como a
elaboração de estatísticas sobre as demandas de consulta e os
perfis de usuários (SÃO PAULO, 2012, on-line).

A Seção II, do Capítulo II dedica-se a esclarecer o que é e como deve ser a gestão de documentos, dados e informações. A partir daí nos deteremos em dois aspectos importantes para a relação que o decreto salienta, entre informação e arquivo: a CADA - Comissão de Avaliação de Documentos e

${ }^{2}$ Cf. artigo $5^{\circ}$, Decreto $n^{\circ} 58.052$, de 16.05.2012.

Inf. Inf., Londrina, v. 22, n. 2, p. 497 - 510, maio/ago., 2017. http:www.uel.br/revistas/informacao/ 
Acesso e o SIC - Serviço de Informações ao Cidadão. No parágrafo único do artigo $5^{\circ}$ são integrantes da "política estadual de arquivos e gestão de documentos":

1. os serviços de protocolo e arquivo dos órgãos e entidades;

2. as Comissões de Avaliação de Documentos e Acesso CADA, a que se refere o artigo 11 deste decreto;

3. o Sistema Informatizado Unificado de Gestão Arquivística e Documentos e Informações - SPdoc;

4. os Serviços de Informações ao Cidadão - SIC. (São Paulo, 2012, on-line).

O artigo $7^{\circ}$ trata de maneira específica da criação e as atribuições do $\mathrm{SIC}$, ele deve ter equipe e infraestrutura tecnológica para qualquer tipo de atendimento. O parágrafo $2^{\circ}$ esclarece que os SICs deverão:

1. manter intercâmbio permanente com os serviços de protocolo e arquivo;

2. buscar informações juntos aos gestores de sistemas informatizados e bases de dados, inclusive de portais e sítios institucionais;

3. atuar de forma integrada com as Ouvidorias, instituídas pela Lei estadual $n^{\circ} 10.294$, de 20 de abril de 1999, e organizadas pelo Decreto $n^{\circ} 44.074$, de $1^{\circ}$ de julho de 1999 (SÃO PAULO, 2012, on-line).

Salientamos que os SICs não têm as mesmas atribuições das Ouvidorias e nem devem ser incorporadas por essas, como na tendência federal (JARDIM, 2012). Ambos devem ser integrados, a relação intrínseca que deve ser estabelecida por força do decreto é com o arquivo e a gestão de documentos.

A Comissão de Avaliação de Documentos e Acesso - CADA - substitui as Comissões de Avaliação de Documentos de Arquivo, e reforça a relação entre documento, informação e acesso. No parágrafo $1^{\circ}$ do artigo 11 é evidente o lugar que a CADA deve estar: no "Gabinete da autoridade máxima do órgão ou entidade". Esse também deve ser o lugar do serviço de arquivo ou do sistema de arquivo. O artigo 12 nos coloca as atribuições da CADA, destacamos os incisos: 
I - orientar a gestão transparente dos documentos, dados e informações do órgão ou entidade, visando assegurar o amplo acesso e divulgação;

II - realizar estudos, sob a orientação técnica da Unidade do Arquivo Público do Estado, órgão central do Sistema de Arquivos do Estado de São Paulo - SAESP, visando à identificação e elaboração de tabela de documentos, dados e informações sigilosas e pessoais, de seu órgão ou entidade;

$(\ldots)$

IV - orientar o órgão ou entidade sobre a correta aplicação dos critérios de restrição de acesso constantes das tabelas de documentos, dados e informações sigilosas e pessoais;

(...)

VIII - atuar como instância consultiva da autoridade máxima do órgão ou entidade, sempre que provocada, sobre os recursos interpostos relativos às solicitações de acesso a documentos, dados e informações não atendidas ou indeferidas, nos termos do parágrafo único do artigo 19 desde decreto;

(...)

Parágrafo único - Para o perfeito cumprimento de suas atribuições as Comissões de Avaliação e Acesso - CADA - poderão convocar servidores que possam contribuir com seus conhecimentos e experiências, bem como constituir subcomissões e grupos de trabalho (SÃO PAULO, 2012, on-line).

A CADA é importante instituição mediadora tanto interna quanto externamente, atuando na gestão de documentos e informação no órgão a que pertence, e intermediadora com o SAESP. Ela ainda intermedia as ações do SIC, e possibilita que em suas sessões os problemas relativos aos arquivos e às informações sejam debatidos, orientando a entidade no sentido de melhor gerir não apenas a informação, mas sobretudo os documentos.

Na UNESP a CADA e o SIC foram instituídos em 2012, tão logo o decreto estadual foi publicado. Os SICs setoriais estão estabelecidos nas unidades universitárias enquanto a Reitoria centraliza todas as solicitações e a elaboração de estatísticas.

Inf. Inf., Londrina, v. 22, n. 2, p. 497 - 510, maio/ago., 2017. http:www.uel.br/revistas/informacao/ 


\subsection{O Processo de Avaliação de Documentos na UNESP}

Discutimos em outra fase da pesquisa a importância e as dificuldades da construção de instrumentos de avaliação de documentos em universidades (BIZELLO, 2014). Ressaltamos aqui que esse processo é fundamental para o conhecimento de toda a produção documental de qualquer instituição. Como instrumentos de gestão eles proporcionam a racionalização burocrática tão necessária para o melhor desempenho administrativo e a tomada de decisão de gestores.

Essa racionalização implica na organização documental que passa a ser inerente ao conhecimento e à construção dos instrumentos de gestão. $O$ estabelecimento da destinação documental apoiada pelo aparato legislativo que incide em inúmeros documentos é fundamental para consolidar o trabalho de pesquisa desenvolvido visando os instrumentos de avaliação.

Na UNESP o plano de classificação e a tabela de temporalidade, tanto de atividades-fim quanto de atividades-meio tem seguido um longo caminho para a consolidação nos anos de 2016 e 2017.

O papel da CADA nesse processo é fundamental uma vez que ela foi e continua sendo, a responsável pela pesquisa junto às Seções Técnicas produtoras e acumuladoras de documentos administrativos e científicos. Esse trabalho foi desenvolvido em etapas:

levantamento de dados; pesquisa e estudo de produção
documental e legislação; sistematização de informações;
elaboração dos instrumentos de gestão; e, em última instância,
debate e aprovação pelas áreas e foros
competentes.(TROITINNO, 2016, p.10)

Dessa maneira, não houve apenas o estabelecimento e a listagem de documentos, mas pesquisa, estudo, sistematização de documentos e informações. Esse processo gerou conhecimento arquivístico que dá suporte à gestão de documentos.

Ainda, o envolvimento de funcionários que manipulam os documentos de arquivo na construção desses instrumentos deu um caráter coletivo a ele, extrapolando o âmbito da CADA. A partir daí não temos tão somente maneiras

Inf. Inf., Londrina, v. 22, n. 2, p. 497 - 510, maio/ago., 2017. http:www.uel.br/revistas/informacao/ 
seguras para empreender a eliminação de documentos ou sua guarda permanente. As informações geradas, no decorrer desse processo, darão subsídios para a classificação da informação. Tarefa nem sempre fácil e rápida.

\section{CONSIDERAÇÕES FINAIS}

O debate em torno das relações entre a Lei de Acesso à Informação e a gestão de documentos em universidades leva em conta não apenas o ditado pela lei, mas formas de produção documental que nos revelam fazeres documentais que passam, muita vezes, ao largo de regras burocráticas.

Ele é essencial uma vez que alarga o conceito de cidadania ligando-o ao documento de arquivo e ao próprio arquivo como um fundamento para a construção e fortalecimento da cidadania, dos direitos políticos, sociais e civis.

Um excelente Serviço de Informação ao Cidadão (SIC) implica não somente em fornecer informações de qualidade ao cidadão, mas em garantir que a documentação, qualquer que seja seu suporte, esteja organizada e, portanto, pronta para o acesso.

O próximo passo, por isso das considerações serem parciais, é o estabelecimento da classificação da informação no âmbito da LAI. O trabalho para a constituição dos instrumentos de gestão é expandido na medida em que é a partir dele que a informação será classificada.

A classificação da informação deve levar em conta que o sigilo é exceção enquanto a regra é o acesso às informações. Isso irá efetivar a prática informacional, consolidará os serviços arquivísticos, assim como proporcionará o exercício do direito à informação pública. 


\section{REFERÊNCIAS}

BIZELLO, M. L. Arquivo, Informação e Gestão de Documentos nas Universidades. In: SILVA, M.C.S. de M. e Oliveira, L.M.V. (Org.). Lei de acesso à informação: Impacto e limites nos arquivos de ciência e tecnologia. Rio de Janeiro: Museu de Astronomia e Ciências Afins, 2014. p.7591.

BRASIL. Lei $n^{\circ} 12.527$, de 18 de novembro de 2011. Regula o acesso a informações previsto no inciso XXXIII do art. $5^{\circ}$, no inciso II do $\S 3^{\circ}$ do art. $37 \mathrm{e}$ no $\S 2^{\circ}$ do art. 216 da Constituição Federal; altera a Lei ${ }^{\circ} 8.112$, de 11 de novembro de 1990; revoga a Lei $n^{\circ} 11.111$, de 5 de maio de 2005, e dispositivos da Lei $n^{\circ} 8.159$, de 8 de janeiro de 1991; e dá outras providências. Disponível em: <http://www.planalto.gov.br/ccivil 03/ ato20112014/2011/lei//12527.htm>. Acesso em: 10 abr. 2015.

JARDIM, J. M. A lei de acesso à informação pública: dimensões políticoinformacionais. Tendências da Pesquisa Brasileira em Ciência da Informação, Brasília, vol. 5, n.1, 2012. Disponível em:

$<$ http://inseer.ibict.br/ancib/index.php/tpbci/article/view/68/110>. Acesso em: 19 fev. 2015.

SÃO PAULO (Estado). Decreto n 58.052, de 16 de maio de 2012.

Regulamenta a Lei federal $n^{\circ} 12.527$, de 18 de novembro de 2011, que regula o acesso a informações, e dá outras providências correlatas. Disponível em: <http://www.al.sp.gov.br/repositorio/legislacao/decreto/2012/decreto-5805216.05.2012.htm>. Acesso em: 10 abr. 2015.

SMIT, J. W.; LATTOUF, R. Os documentos da pesquisa científica na ótica da Lei de Acesso à Informação: algumas propostas e alguns desafios. In: SILVA, M.C.S. de M. e OLIVEIRA, L.M.V. (Org.). Lei de acesso à informação: Impacto e limites nos arquivos de ciência e tecnologia. Rio de Janeiro: Museu de Astronomia e Ciências Afins, 2014. p.115-143.

TROITIÑO, S. (coord.). Plano de classificação e tabela de temporalidade de documentos da UNESP: atividades-meio. São Paulo: Cultura Acadêmica, 2016.

\section{Title}

Organization and access to information in the university environment

\section{Abstract:}

Introduction: This paper aims to discuss the Law on Access to Information within 
universities and, in a more specific way, the implementation of LAl at the State University of São Paulo "Júlio de Mesquita Filho" - UNESP. Objective: It studies the importance of record management for the organization and representation of information in universities. Methodology: The methodology used was that of bibliographic research at a first moment since the discussion about the Law of Access to Information is relatively new. We explore the subject in a qualitative way and aim to discuss it in UNESP without colluding in general the university as an institution. Results: Thus the study presents initial results crossing the bibliographical discussion and the research of observational character. Conclusions: The law on access to information gave greater visibility to university archives, in the case of UNESP, and the archival organization and the construction of document evaluation tools provided the basis for the operationalization of more integrated systems besides giving greater subsidy to the Service of Information to the Citizen.

Keywords: Law on Access to Information. Record Management. Archive. University. Appraisal.

\section{Titulo}

Organización y acceso a la información en el ambiente universitario

\section{Resumen:}

Introducción: Este trabajo objetiva discutir la Ley de Acceso a la Información en el ámbito de las universidades y de manera más puntual la implantación de la LAl en la Universidad Estadual Paulista "Júlio de Mesquita Filho" - UNESP. Objetivo: Hace un estudio de la importancia de la gestión de documentos para la organización y representación de la información en las universidades. Metodología: La metodología utilizada fue la de la investigación bibliográfica en un primer momento, ya que la discusión sobre la ley de acceso a la información es relativamente nueva. Exploramos el tema de manera cualitativa y objetivamos discutirlo en la UNESP sin dejar de cotejar de manera general a la universidad como institución. Resultados: Así el trabajo presenta resultados iniciales cruzando la discusión bibliográfica y la investigación de carácter observacional. Conclusiones: La Ley de Acceso a la Información impulsó una mayor visibilidad a los archivos universitarios, en el caso de la UNESP, siendo que la organización archivística y la construcción de instrumentos de evaluación documental proporcionaron las bases para la operacionalización de sistemas más integrados además de dar mayor subsidio al Servicio de Información al Ciudadano.

Palabras clave: Ley de Acceso a la Información. Documento. Archivo. Universidad. Evaluatión de Documentos.

Recebido: 30.08 .2017

Aceito: 30.09 .2017

Inf. Inf., Londrina, v. 22, n. 2, p. 497 - 510, maio/ago., 2017. 